\title{
African climate-vegetation interaction since the last glacial period
}

\author{
Ilham Bouimetarhan', L. Dupont', C. Itambi² and J.-B.W. Stuut ${ }^{1,3}$
}

Bremen, Germany, 4-8 November 2012

The global distribution and composition of vegetation is largely controlled by climate. Vegetation can however, exert an important influence on surface energy fluxes and the hydrological cycle through alteration of the surface albedo and biogeochemical processes, thus impacting climate locally. In Africa, where climate and vegetation data are sparse, our understanding of the interaction between vegetation and climate and its consequences for the formation and maintenance of terrestrial ecosystems is still poor. But this understanding is crucial to identify feedback effects on different spatial and temporal scales.

This four-day workshop focused on the study of dynamic interaction of climate and vegetation by combining a large set of African vegetation and hydrology records. These sedimentary records were recovered from marine and terrestrial sites in West, East and Southern Africa. Forty scientists from 13 countries participated in the workshop, 11 of them are based in Africa.

The workshop began with a two-day educational program for early-career scientists. Keynote lectures provided networking opportunities with international experts on African vegetation, meteorology, climate observations, and model simulations. The presentations addressed the topics climate-vegetation interactions, model simulations of past vegetation changes, and the understanding of modern climate processes. The early career scientists had the opportunity to visit the labs at MARUM, the IODP core repository center, and the Department of Geosciences, and were also familiarized with the various funding opportunities for collaborative research projects at German institutions.

The second part of the workshop consisted of five oral presentation sessions dealing with: 1) present-day vegetation, environmental degradation, meteorology and remote sensing; 2) past vegetation and its response to abrupt climate change in West Africa; 3) South African paleoenvironments; 4) hydroclimate and vegetation in East Africa; and 5) an open discussion on scientific challenges in Africa and futures activities.

A number of scientific questions emerging from the workshop reflected that African scientists are more involved in research on the actual consequences of ongoing climate change and their impact on local communities, rather than on more fundamental questions regarding climate mechanisms. For example, the consequences of present-day rising sea levels are of greater concern to communities than understanding sea-level changes in the past. There

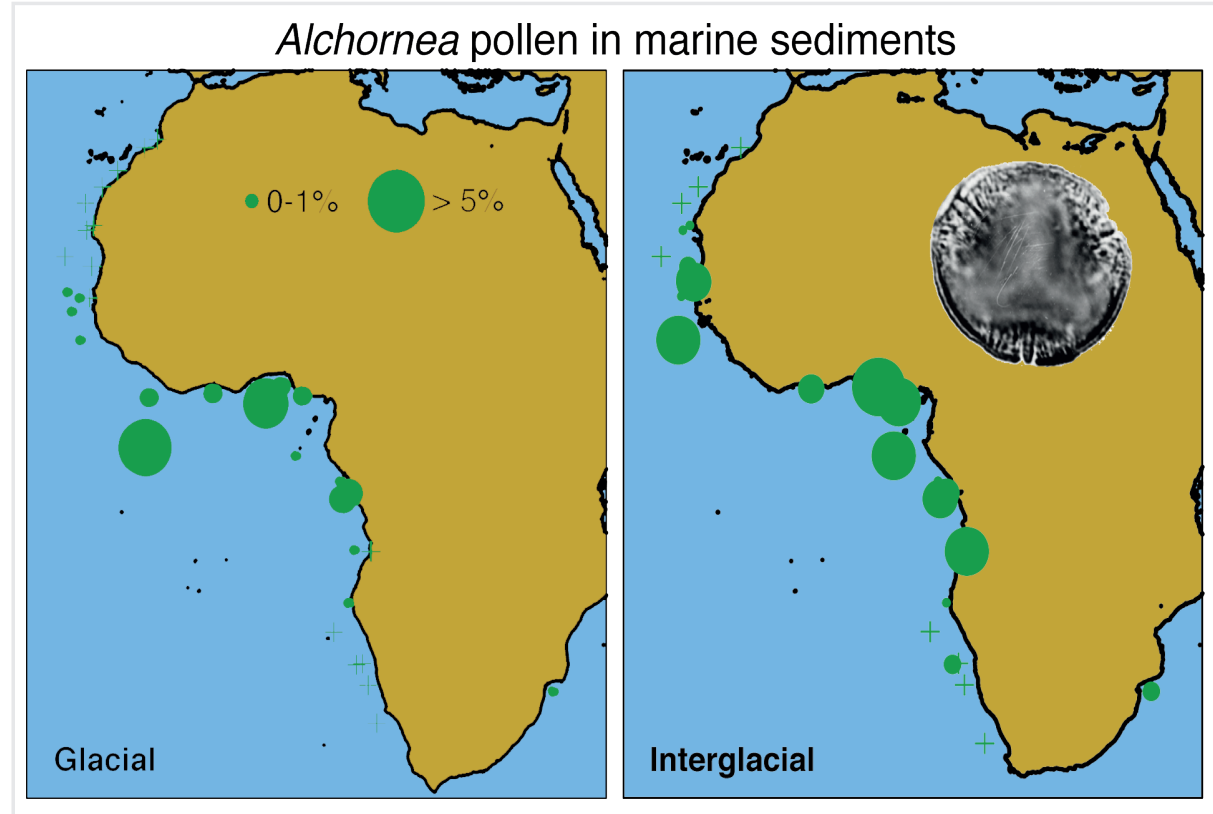

Figure 1: Alchornea pollen distribution (\% of total pollen) in the marine sediment along the African coast illustrates orbital scale vegetation changes. The maps show that during the Last Glacial Maximum, (LGM, left) outside the equatorial region only, very little Alchornea pollen are found. This suggests a reduction of the tropical rain forest area compared with the mid-Holocene (right). Figure modified from Jolly et al. (1998), Elenga et al. (2000) and Dupont (2011).

are also concerns about the intensification of rainfall already leading to increased erosion of tropical soils, and potentially damaging infrastructure and drinking water facilities.

Several key research foci were agreed on in the plenary discussion on the last day of the workshop: a) comparison of terrestrial and marine records; b) addressing age model uncertainties; c) the driving forces of climate and vegetation change, including the Atlantic meridional overturning circulation, Indian Ocean sea surface temperatures, insolation, ITCZ/tropical rainbelt migration; d) East-West versus North-South gradients; e) timing and mechanism leading to the African Humid Period. Possibilities are presently being explored to collaborate on these research foci.

Proxy studies were also discussed, including how to improve vegetation reconstructions using pollen analysis with emphasis on provenance, transport pathways and modern analogs (e.g. Fig. 1). New proxy types should be thoroughly reviewed before application, especially stable hydrogen isotopes. But, stable carbon isotopes, a common proxy for the contribution of $\mathrm{C}_{3}$ - and $\mathrm{C}_{4}$-plants, should also be reviewed because interpretations can vary locally depending on the impact of temperature or aridity on the vegetation.
The importance of involving people from the modeling community was also discussed, since patterns of past vegetation changes can be used to improve climate models and the accuracy of future predictions. Finally, the need for better communication between marine and terrestrial research communities, and between data and modeling communities was identified and discussed. It is acknowledged that the availability of climate information in Central Africa is sparse. This gap needs to be filled in order to obtain a more complete overview of African climate-vegetation interaction.

\section{AFFILIATIONS}

${ }^{1}$ Center for Marine Environmental Sciences (MARUM), University of Bremen, Germany

${ }^{2}$ Department of Geosciences, University of Bremen, Germany

${ }^{3}$ Royal Netherlands Institute for Sea Research (NIOZ), Den Burg, The Netherlands

\section{CONTACT}

Ilham Bouimetarhan: bouimetarhan@uni-bremen.de REFERENCES

Dupont L (2011) Quat Sci Rev 30: 3589-3602 Elenga H et al. (2000) J Biogeog 27: 621-634 Jolly D et al. (1998) J Biogeog 25: 1007-1027 